\title{
Mobile Commerce Switching Intentions in Thai Consumers
}

\author{
Ms. Kedwadee Sombultawee \\ Lecturer at Silpakorn University, \\ Faculty of Management Science, \\ Silpakorn University, Thailand
}

Doi: 10.1515/mjss-2017-0049

\begin{abstract}
This research applies an extended Unified Theory of Adoption and Use of Technology (UTAUT) model to consumer intentions to switch from other retail channels to mobile commerce in Thailand. Mobile commerce is a rapidly growing segment of the consumer market, but remains in an early stage of adoption in many markets. A survey of Thai consumers $(n=458)$ was conducted online and analyzed using a structural equation modeling (SEM) approach. Findings showed that the extended UTAUT model, which included online social support and convenience, significantly explained the consumer decision to engage in mobile commerce. However, direct incentives (discounts and referral codes) were not significant. The implication of these findings is that mobile commerce providers need to focus on building social support for the technology itself, rather than relying on marketing tools like discounts or referral codes if they want to shift sales away from other retail channels.
\end{abstract}

Keywords: mobile commerce, Thailand, consumer adoption, UTAUT, social support, channel switching

\section{Introduction}

Mobile commerce (or m-commerce) is business and consumer commerce conducted through mobile channels, including mobile web and app-based sales of tangible and intangible goods and services and use of mobile payments (Chong, 2013). Mobile commerce is still a minority share of total e-commerce; for example, 2014 US figures indicated it made up about $\$ 35$ billion (or $11.6 \%$ of total e-commerce) (Meola, 2016). As of Q4 2015, it is estimated that about $31 \%$ of mobile phone users in Thailand had made at least one m-commerce purchase, indicating a high level of market penetration compared to other countries in the region (Statista, 2016). Mobile commerce is part of many firm's multi-channel or omni-channel marketing strategies, with mobile sales channels, such as apps or mobile websites, incorporated alongside traditional sales channels like retail stores and e-commerce sites (Maity \& Dass, 2014). However, consumers do not prefer to use mobile commerce for all types of transactions; instead, mobile commerce is typically used for relatively simple transactions and transactions where the goods are meant to be used in mobile contexts (such as downloadable or streaming media) (Maity \& Dass, 2014). Additionally, consumer demographics and technology usage preferences also influence whether they will use mobile commerce (Chong, 2013).

The Universal Theory of Adoption and Use of Technology (UTAUT) model is an obvious choice for studying consumer switching intentions for existing technology, since it addresses both the technological and social conditions of technology adoption (Venkatesh, Morris, Davis, \& Davis, 2003). Furthermore, with a predictive value of around $50 \%$ on average (Dwivedi, Rana, Chen, \& Williams, 2011), this could be an effective tool for understanding consumer switching intentions and behaviors. The adoption of mobile technology has routinely been studied using the UTAUT 
(Alkhunaizan \& Love, 2012; Jaradat \& Al Rababaa, 2013; Wang \& Wang, 2010). However, none of these studies have examined switching between different service providers or channels for the same type of service, but have instead studied the initial technology adoption. A changing consumer environment also suggests that there needs to be further extension of the UTAUT model to account for such decisions, including for example online social support (Lin \& Anol, 2008) and convenience (Min, Ji, \& Qu, 2008) as facilitating conditions for technology adoption. Additionally, retail service providers often attempt to influence consumers through direct switching incentives (Andrews, Benedicktus, \& Brady, 2010), which is not accounted for the in UTAUT model. Thus, there is a gap in the research in two specific areas. The first area is the lack of research into switching behavior, rather than the initial adoption behavior. The second is in the specific context of retail channel choice in today's market, which include aspects not considered in the original formulation by Venkatesh, et al. (2003). This study attempts to fill these gaps.

The purpose of this research is to examine consumer switching intentions from existing retail channels (brick and mortar and e-commerce) of retailers they already interact with. It applies an extended Unified Theory of the Adoption and Use of Technology (UTAUT) to examine switching intentions.

\section{Literature Review}

\subsection{Mobile commerce switching behavior}

This research is mainly concerned with mobile commerce channel switching behavior. Consumer channel switching refers to the consumer's choice of another sales channel from the same or different retailer for the same product (Pookulangara, Hawley, \& Xiao, 2011). For example, consumers may choose to purchase a given product either from an online store or the associated physical retail store. Consumers may also engage in channel switching between retailers; for example, using one retailer's physical store to examine a product and then buying it from another retailer's electronic commerce site (Heitz-Spahn, 2013). For the purposes of this research, we examine consumer retail channel switching from either physical or non-mobile e-commerce channels to mobile commerce, but do not address the question of free-riding (purchase from another retailer). It also only focuses on goods that could be purchased through multiple channels, excluding mobile purchases such as streaming entertainment or in-app purchases designed for use with a mobile device. This study does not address information channel switching, given that consumers may use varied information channels already, including online and mobile channels (Solomon, Bamossy, Askegaard, \& Hogg, 2013).

There are several reasons consumers may engage in channel switching. Consumers may already be comfortable in a multi-channel shopping environment and may have strong requirements for cost, convenience or selection (Heitz-Spahn, 2013). There may also be sociodemographic factors, including income and age (Heitz-Spahn, 2013). The product characteristics also influence channel switching (Maity \& Dass, 2014). For example, e-commerce and in-store shopping experiences offer more detail and information about the product, and are often preferred for complex shopping choices (Maity \& Dass, 2014). Firms may also differentiate pricing between channels to encourage consumers to switch channels, which could have an effect (Kauffman, Lee, Lee, \& Yoo, 2009). However, this strategy may not be ideal since this can result in cannibalization of existing customers, rather than increasing market share (Falk, Schepers, Hammerschmidt, \& Bauer, 2007).

Channel switching is not a problem per se for retailers undertaking a multi-channel or omnichannel retailing strategy, whose aim is to enable shoppers to buy, service, and return products seamlessly between all channels (Verhoef, Kannan, \& Inman, 2015). Retails that pursue the omnichannel strategy, in particularly, have made a strategic choice of offering consumers the option to use any channel (Verhoef, et al., 2015). However, this does not mean that the consumer's channel choice or channel switching intention or behavior is meaningless for the firm. using online channels have lower costs to serve (the amount making a sale costs the company) and they may have increased revenues (spending more with the company) (Gensler, Leeflang, \& Skiera, 2011; 
Verhoef, Kannan, \& Inman, 2015). Furthermore, multichannel customers are likely to have a higher consumer value than single-channel customers (Neslin \& Shankar, 2009). At the same time, the multichannel retailer faces challenges such as supply chains for different channels and integrated marketing campaigns that make sense in this context (Neslin \& Shankar, 2009). Thus, even if retailers encourage their consumers to switch channels seamlessly, it is still helpful for them to understand why consumers switch and how this influences their switching behavior.

This research examines distribution channel switching intentions at the pre-purchase stages. A consumer intention can be briefly defined as a decision to undertake a specific behavior, which is then translated into a consumer behavior (Kardes, Cronley, \& Cline, 2011). The intention to study consumer intentions was made because it is more difficult to study actual behaviors, which can vary and may be diverted (for example through lack of resources or because the consumer changes their mind) (Ajzen, 2008). The pre-purchase stage of consumer decision making consists of a process of need identification and alternative identification, comparison, and selection, leading to the purchase stage of action (Kardes, et al., 2011). While omni-channel retailing could lead to continued consumer channel switching (for example, during returns or repairs) (Verhoef, et al., 2015), this study focuses on the pre-purchase stage for the initial consumer decision to use the mobile channel.

\subsection{UTAUT model}

The UTAUT model was proposed as an integrative model of user technology acceptance, incorporating elements of eight previous conflicting models (Venkatesh, Morris, Davis, \& Davis, 2003). The UTAUT model (Figure 1) incorporates four technology-related factors, including: performance expectancy (what the user believes the technology will do); effort expectancy (how difficult they expect it to be to use); social influence (social norms surrounding its use); and facilitating conditions (factors that enable or disable technology use) (Venkatesh, et al., 2003). Of these factors, performance expectancy, effort expectancy, and social influence are believed to contribute directly to behavioral intentions, while facilitating conditions contribute directly to use behavior (Venkatesh, et al., 2003).

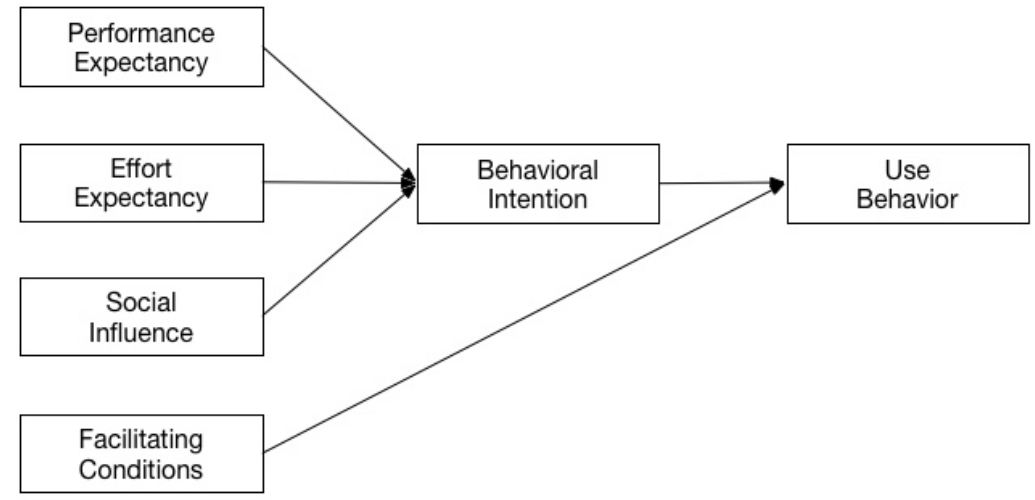

Figure 1: The Unified Theory of Acceptance and Use of Technology (UTAUT)

Source: Adapted from Venkatesh, et al., 2003, p. 447

Tests of UTAUT have found it generally predictive of technology usage. For example, Venkatesh, et al.'s (2003) original formulation testing found that it predicted about $69 \%$ of variance in technology acceptance, compared to between $17 \%$ and $53 \%$ of the models it drew from. However, a metaanalysis of the relatively small numbers of studies that have actually used this model has not had as strong a result (Dwivedi, Rana, Chen, \& Williams, 2011). These authors found that the predictive 
value of the model was closer to $50 \%$ for most studies (Dwivedi, et al., 2011). Thus, this model may be used but it must be used cautiously.

Several previous studies have used the UTAUT to assess mobile Internet or mobile commerce technology adoption, although none have examined mobile commerce channel switching. One group of authors examined mobile Internet adoption in Taiwan $(n=343)$, using a structural equation modeling (SEM) approach (Wang \& Wang, 2010). They found significant influences of all factors except perceived playfulness (a model extension), with a high predictive value for behavioral intention $\left(R^{2}=0.650\right)$. They concluded that the UTAUT model, with appropriate extensions, could explain the adoption of mobile Internet (Wang \& Wang, 2010). An extended UTAUT model was also used in a study of Saudi Arabian consumers and their intention to adopt mobile commerce $(n=574)$ (Alkhunaizan \& Love, 2012). These authors added trust in the technology and cost factors, and also studied demographics (age and gender). Their regression analysis showed that performance expectancy was the most significant factor in adoption, followed by cost and effort expectancy; social influence and trust were not significant (Alkhunaizan \& Love, 2012). A study of Jordanian consumer acceptance of mobile commerce ( $n=447)$ had slightly different findings (Jaradat \& Al Rababaa, 2013). These authors' SEM analysis showed that social influence was the strongest factor, followed by effort expectancy and performance expectancy (Jaradat \& Al Rababaa, 2013). These studies show that there is still conflicting information about factors in consumer choice of mobile commerce, which could result from different demographic, cultural or technological contexts. However, application of UTAUT remains relatively rare, as noted by Dwivedi, et al. (2011). This leaves an opportunity for the present research to contribute to understanding mobile commerce acceptance.

The elements of the UTAUT model are used as the basis for the first three hypotheses, which are proposed in line with previous findings on the adoption of mobile commerce. Facilitating conditions are excluded because actual use is not tested. These hypotheses are stated:

Hypothesis 1: Performance expectancy of mobile commerce is positively associated with channel switching behavior.

Hypothesis 2: Effort expectancy of mobile commerce is positively associated with channel switching behavior.

Hypothesis 3: Social influence is positively associated with channel switching behavior.

\subsection{Extended Framework}

Previous studies utilizing the UTAUT have routinely extended the framework in order to allow for a more contextually appropriate application. This research also develops an extended framework, with some aspects taken from previous UTAUT studies and others being specific to the online commerce situation.

\subsubsection{Online social support}

The first factor included in the UTAUT-based model is online social support. Online social support can be defined as evidence of positive social support in an online context (Lin \& Anol, 2008). Lin and Anol (2008) examined online social support as a factor in online learning adoption, operationalizing it as use of instant messaging (IM) services. The authors found that it did contribute to behavioral intention to use online learning, but did not play a role as a facilitating factor. In the context of mobile commerce, online social support may be more appropriately operationalized as exposure to online reviews, which provide both practical product information and social support signals (Sun, Youn, Wu, \& Kuntaraporn, 2006). These reviews are commonly defined as electronic word of mouth (EWOM), which provides social support for the purchase decision and provides information from a trusted source (Kardes, et al., 2011). A previous study on Internet users in Japan found that mobile commerce users' provision of word of mouth (WOM) was more likely to be driven by social intention and social cognition, implying a potentially more important role for online social support than users of other electronic commerce channels (Okazaki, 2009). Electronic word of mouth (EWOM) is distinct from word of mouth (WOM) are different 
because EWOM is not typically built on personal knowledge and trust of the recommender, but instead on the reputation of the recommender (for example upvotes) and the clarity and relevance of information provided (Goldsmith, 2009). These studies provide evidence that online social support may be an important factor in mobile commerce channel switching. Furthermore, online social support (EWOM) is distinct from generalized social support for adoption of technology. Therefore, the fourth hypothesis is:

Hypothesis 4: Online social support is positively associated with mobile commerce channel switching.

\subsubsection{Convenience}

One of the factors that sets mobile commerce apart from other forms of e-commerce or brick and mortar commerce channels is convenience, which refers to the ease with which the consumer can make the purchase (Solomon, et al., 2013). Convenience may occur in space, time, or difficulty dimensions (Solomon, et al., 2013), and to some extent all three of these dimensions apply here. Consumers typically have access to their mobile devices at any time and do not need to be located in a particular place to use them. A model of mobile commerce adoption proposed for the Chinese market based on an extended UTAUT argued that convenience would be a significant factor in behavioral intention to use mobile commerce (Min, Ji, \& Qu, 2008). Specifically, convenience and cost were the factors that were identified as facilitating conditions in actual use (Min, et al., 2008). For this study, these two factors are differentiated, since convenience and cost may have different influences. Min, et al. (2008) did not empirically test their model of mobile commerce adoption. However, other studies examining the topic have identified convenience as a potential factor. For example, one study examined mobile commerce using a modified Technology Acceptance Model (TAM) framework (Wu \& Wang, 2005). (The TAM is one of the eight technology adoption models incorporated into the UTAUT (Venkatesh, et al., 2003).) The authors identified convenience as part of the benefits of using mobile commerce. However, this study is old enough that the underlying technology has changed; for example, many more consumers now have smartphones, while in Wu and Wang's (2005) study most users only used their phones as a convenience tool. A more recent study also incorporated a revised TAM, this time with the extension of uncovering gender differences (Okazaki \& Mendez, 2013). These authors found that perceptions of convenience of mobile commerce were influenced by intrinsic attributes (portability and interface design, contributing to usability), and external attributes (simultaneity, speed, and searchability of mobile commerce) (Okazaki \& Mendez, 2013). Once again, however, this research did not follow through completely, since the authors did not then study the effect of convenience on usage intentions. Thus, the literature surrounding convenience of mobile commerce is mixed. While many authors have made theoretical arguments regarding the relationship of convenience to usage intentions for mobile commerce, the actual empirical evidence is limited. To help fill that gap, convenience is added as an extension to the UTAUT model as follows:

Hypothesis 5: Convenience is positively associated with mobile commerce channel switching.

\subsubsection{Direct switching incentives}

The third extension of the UTAUT model is direct switching incentives. A switching incentive is something offered to the consumer by the retailer in order to encourage the consumer to switch suppliers, products or sales channels (Andrews, Benedicktus, \& Brady, 2010). For example, communications service providers routinely offer discount bundles in order to encourage consumers to switch from competitors, or cash incentives to lower switching costs (Andrews, et al., 2010). In terms of earlier models of consumer adoption of mobile commerce, the switching incentive can be viewed as reducing the cost associated with switching from other channels to the mobile channel (Min, et al., 2008). This research examines two possible types of switching incentives, including referrals from existing customers and discount promotions. Mobile user referrals may be encouraged as part of word of mouth campaigns to access existing user's social networks and provide social proof for the service (Okazaki, 2008). This study did find that WOM 
information channels (user referrals) influenced attitudes and behaviors (Okazaki, 2008). Discounts have not been tested directly, but as cost-lowering promotional strategies are potentially supported by Min, et al.'s (2008) theoretical extended framework. User referrals and discounts are different in nature, as they do have a social element (Okazaki, 2008), while discounts typically do not. However, referrals and discounts are often combined; for example, it is common to offer both current and new customers a small discount for successful switching (Kumar, Peterson, \& Leone, 2010). Thus, the effects of referrals and discounts could be difficult to distinguish, as both serve to reduce switching costs and they may be used in combination (Kumar, et al., 2010). To determine whether direct switching incentives do influence the behavioral intention to switch to mobile commerce channels, the following hypothesis will be tested:

Hypothesis 6: Direct switching incentives (referrals and discounts) positively associated with mobile commerce channel switching.

\subsection{Research Model}

The research model incorporates the UTAUT $(\mathrm{H} 1$ through $\mathrm{H} 3)$ and three additional extending factors, including online social support, convenience, and direct incentives ( $\mathrm{H} 4$ through $\mathrm{H} 6)$ (Figure 2). In addition, moderating variables of gender, age, and income level were included, on the basis that demographic characteristics influence consumer decisions and availability of resources (Kardes, et al., 2011).

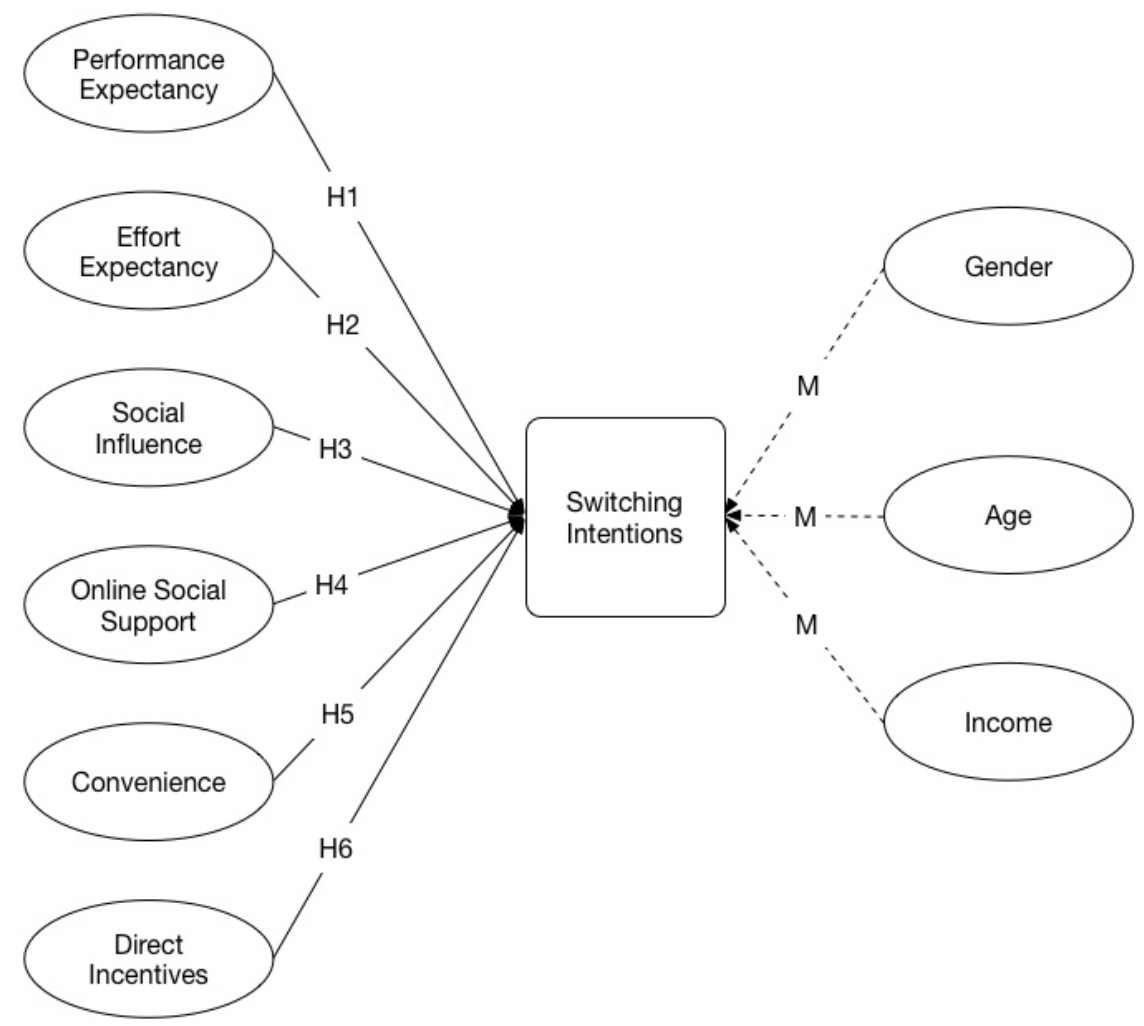

Figure 2: Research model 


\section{Methodology}

\subsection{Population and sample}

The population of interest of this study was Thai consumers (age 20+). Following recommendations on the sample size for SEM (Westland, 2010), a minimum sample size of 400 consumers was established. The sample was selected using a convenience sample of online users, who were recruited via announcements on Facebook and other social media sites. While an online sample selection is not ideal in all situations because it is exclusionary (Sue \& Ritter, 2012), in this case it was acceptable because at least one online device would be required to engage in channel switching anyway. To increase sample randomness, a snowball technique was used, with participants asked to pass the survey to others. The response rate is not known due to the open recruitment strategy. However, a total of 474 surveys were submitted, but 56 surveys were excluded because they were not finished, leading to a completion rate of $88.2 \%$. The final sample size $(n=418$ consumers) exceeded the minimum.

\subsection{Measurement}

The online survey (Attached in the Appendix) was based on previous instruments (Venkatesh, et al., 2003; Lin \& Anol, 2008), with some items adapted from but not directly taken from previous studies. Each of the factors and outcome variable was measured using five-point Likert scales, with three items in each of the scales. All scales achieved $\alpha>0.8$, indicating no adjustment was needed for internal consistency. Demographics and technology and mobile commerce usage information was also collected. The outcome variable (Switching Intention) was measured using a scenario, rather than a past purchase, because it had been previously determined that not all participants had switched providers.

\subsection{Data collection}

Data was collected using a Google-based survey instrument designed by the researcher. The instrument was available in both English and Thai, to allow respondents a choice of languages. The instrument was tested for language invariance using a backward and forward translation strategy. First, the researchers designed the survey in Thai, and then translated the survey into English. An unrelated third party professional translator was then hired to re-translate the resulting English questionnaire back to Thai, and the two resulting questionnaires were compared to ensure the instruments were consistent. Adjustments were made as needed. Data collection was conducted for a period of one month in 2016. Following survey closure, the English and Thai surveys were combined into a single dataset.

\subsection{Data analysis}

Data analysis was conducted using SEM in SPSS AMOS, and outcomes were evaluated using standard thresholds and interpretations as identified by Byrne (2016). Descriptive statistics were also prepared for demographics and technology usage, which helps explain the characteristics of the sample. Exploratory factor analysis (EFA) was conducted first, to refine the measurement model. Confirmatory factor analysis (CFA) was then used to test the structural model.

\section{Findings}

The findings incorporate descriptive statistics of demographics and mobile commerce usage, along with the presentation of the research model. 


\subsection{Demographics and mobile commerce usage}

The sample was slightly more female $(52.4 \%)$ than male $(47.6 \%)$, but the sample is not significantly unequally distributed $\left(\chi^{2}=0.957, p=0.328\right)$. The sample was also noticeably young, with age ranges including: $20-30$ years $(56.7 \%)$; $31-40$ years $(29.2 \%) ; 41-50$ years $(10.8 \%)$; and $51+$ years $(3.6 \%)$. In terms of educational level, respondents were generally highly educated. Categories included: less than Bachelor level (34.9\%); Bachelor level (48.3\%); and higher than Bachelor level $(16.7 \%)$.

Respondents were asked about communications technology access and use and use of mobile commerce. Most of the respondents had desktop/laptop Internet access $(87.1 \%)$, but more had mobile (phone or tablet) access (92.1\%). All had either desktop or mobile access, as this was used as a screening question. Respondents were mainly moderate Internet users, with most using the Internet (desktop or mobile) 3-4 hours a day $(72 \%)$. A smaller number were heavy users $(>4$ hours a day) $(15.6 \%)$ or light users $(<3$ hours) $(12.4 \%)$. Just over half $(55.3 \%)$ had used mobile commerce at least once. Thus, the participants were relatively technologically capable and did not have technology barriers to mobile commerce.

\subsection{Reliability and validity}

Scales were assessed for reliability and validity using several metrics (Table 1). These tests included Reliability (CR > 0.7); Convergent Validity (AVE > 0.5); and Discriminant Validity (MSV < AVE, ASV < AVE). As the results show, all scales met these characteristics.

Table 1: Reliability and convergent and discriminant validity of the scales

\begin{tabular}{|c|c|c|c|c|}
\hline Scale & CR & AVE & MSV & ASV \\
\hline PE & 0.787 & 0.516 & 0.512 & 0.505 \\
\hline EE & 0.736 & 0.591 & 0.524 & 0.561 \\
\hline SI & 0.812 & 0.712 & 0.612 & 0.618 \\
\hline OSS & 0.712 & 0.512 & 0.503 & 0.501 \\
\hline CO & 0.767 & 0.612 & 0.518 & 0.520 \\
\hline DI & 0.792 & 0.618 & 0.581 & 0.564 \\
\hline SWI & 0.813 & 0.712 & 0.681 & 0.644 \\
\hline
\end{tabular}

\subsection{Research model}

The completed research model (Figure 3) shows that all factors except direct incentives influenced behavioral intention to use mobile commerce. The goodness of fit of the measurement model was acceptable based on standard measures $(\mathrm{GFI}=0.95, \mathrm{AGFI}=0.91, \mathrm{NFI}=0.95 \mathrm{CFI}=0.98, \mathrm{RMSEA}$ $=0.03, \chi^{2} / \mathrm{df}=1.62$ ). Reliability and convergent and discriminant validity were also measured and found to be appropriate $(\mathrm{CR}=0.80, \mathrm{AVE}=0.65$, $\mathrm{MSV}=0.59$, $\mathrm{ASV}=0.51)$. Goodness of fit for the structural model was similar to the measurement model $(\mathrm{GFI}=0.92, \mathrm{AGFI}=0.92, \mathrm{NFI}=0.94 \mathrm{CFI}=$ $\left.0.97, \mathrm{RMSEA}=0.04, \chi^{2} / \mathrm{df}=1.55\right)$. Thus, the model was accepted as appropriately fitted to the data and showing evidence of reliability and validity.

The overall predictive capability of the model was relatively good, though not perfect $\left(R^{2}=\right.$ 0.602). Five of the factors had significant relationships to switching intentions according to their path coefficients, including Performance Expectancy, Effort Expectancy, Social Influence, Online Social Support, and Convenience. However, Direct Incentives did not have a significant relationship. Of these factors, Effort Expectancy had the highest path coefficient, followed by Performance Expectancy and Social Influence. The outcome of these tests allow for the three hypotheses associated with the core UTAUT model $(\mathrm{H} 1, \mathrm{H} 2$ and $\mathrm{H} 3)$ to be accepted. Furthermore, extended factors including Online Social Support $(\mathrm{H} 4)$ and Convenience $(\mathrm{H} 5)$ can also be accepted. However, Direct Incentives (H6) cannot be accepted. Of the three moderating variables assessed, only gender had a small significant effect on Switching Intentions, with age and gender insignificant. 
The coding $(0=$ female, $1=$ male $)$ indicates that male participants have slightly higher switching intentions than female participants.

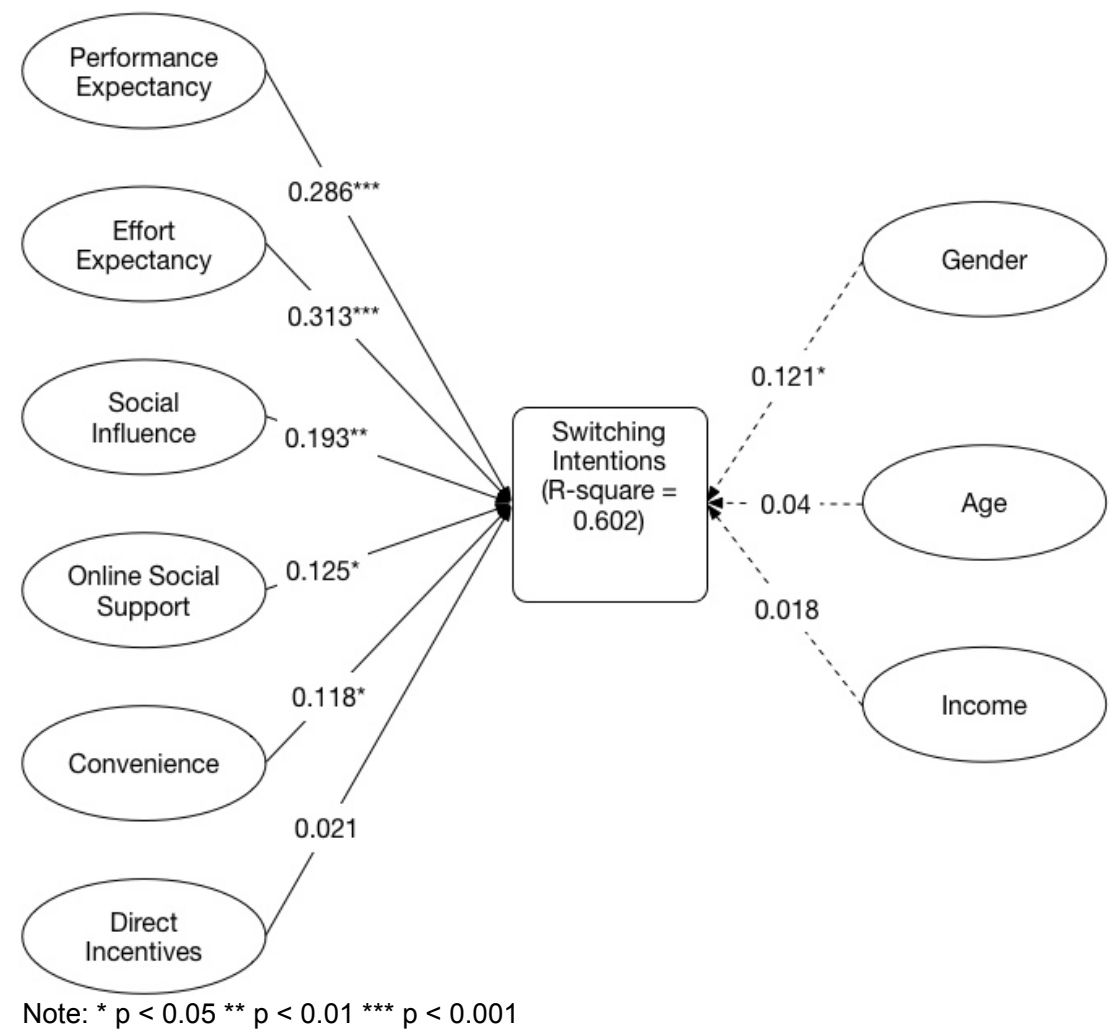

Figure 3: Research model and path coefficients

\section{Discussion}

The results of this research supported the UTAUT model in the situation of channel switching from other retail channels to mobile commerce. In particular, the influence of effort expectancy and performance expectancy was high, although social influence was less important. Online social support and convenience were additional factors that influenced channel switching, although direct incentive was not a significant factor. These results are not surprising given the state of the evidence for each of these factors.

The evidence for application of UTAUT to the adoption of mobile commerce is well supported by existing studies, which have generally shown it to be a reliable model for this decision, particularly when extended with context-specific variables (Alkhunaizan \& Love, 2012; Jaradat \& Al Rababaa, 2013; Min, Ji, \& Qu, 2008; Wang \& Wang, 2010). These findings also support the UTAUT model, but are not strictly a replication of previous studies. The adoption of mobile commerce is in many cases not just a neutral channel choice or the only channel from which something can be obtained (except intangible mobile goods and services like streaming audio and video or in-app purchases). Instead, mobile commerce is typically a consumer decision to switch channels from instore retail or other forms of e-commerce. This is often a deliberate choice by retailers who establish multi-channel or omni-channel marketing strategies to try to capture more of the market or to increase consumer convenience (Maity \& Dass, 2014). The evidence on consumer channel 
switching is limited, and this is a question that needs more development in the literature. However, even though the UTAUT model has been under-utilized in mobile commerce adoption and channel switching (as it has in other technology adoption studies according to Dwivedi, et al. (2011)), this research supports its reliability for explaining the consumer channel switching decision.

The extensions of the UTAUT model met with varying success. All three of the extended factors had lower path coefficients, contributing less to the outcome of behavioral intention to switch to mobile commerce than the core UTAUT factors. However, online social support and convenience were significant. The importance of online social support was identified by a previous study in online learning (Lin \& Anol, 2008), but has not been applied directly to the choice of online commerce channels or channel switching questions. However, previous studies have identified relationships between mobile WOM and social support (Sun, et al., 2006; Okazaki, 2009). Thus, this factor did deliver the expected value, although the role of online social support does still need to be clarified. Convenience was also an obvious factor in mobile commerce adoption and channel choice, since it is a significant issue of technology access (Min, et al., 2008). Other studies have also identified convenience as a possible factor in mobile commerce choice, although these studies have not actually empirically tested the factor (Okazaki \& Mendez, 2013; Wu \& Wang, 2005). Thus, this research contributes by testing the importance of convenience to mobile channel switching. The final factor of direct incentives was not significant in the model. This factor was included following Min, et al.'s (2008) identification of cost as a factor in mobile commerce adoption, as well as the popularity of such incentive offers as an attempt to encourage channel switching or channel choice (Andrews, et al., 2010). It is possible that direct incentives are more important for some categories of mobile commerce or for some users than others. This would be consistent with earlier studies, which have identified differences in consumer demographics and technology usage (Chong, 2013; Maity \& Dass, 2014).

\section{Conclusion and Recommendations}

In conclusion, the UTAUT model, along with online social support and convenience, can be used to partially explain consumer channel switching to mobile commerce from other retail channels. This finding is important because relatively few studies have explored channel switching to mobile commerce, even though it is acknowledged to be a potential problem for retailers whether consumers are switching between their own channels or those of their competitors (Falk, et al., 2007; Heitz-Spahn, 2013). This is a general problem in the literature of technology adoption, with few studies addressing why or how technology users may change from one technology to another. There is also limited information in the literature about why consumers choose to switch channels with the same retailer. Thus, this is a contribution to the theoretical literature on consumer behavior, which will become more important as retailers move toward multi-channel or omni-channel strategies. This shift has not happened for many industries in Thailand, with many retailers operating strictly in one channel, but given the speed of technology adoption - especially mobile shopping - it cannot be far behind. Thus, the findings are also important because of its implications for retailers. Many retailers have adopted a multi-channel or omni-channel retailing approach in order to increase their mobile market penetration and take advantage of mobile consumer opportunities (Maity \& Dass, 2014). Despite the increasing availability of mobile commerce, consumers have remained unwilling to switch, with a relatively slow adoption rate in many markets including Thailand. This research shows that there are no technological barriers to mobile commerce adoption, and in fact there is strong evidence that the social situation and convenience of the mobile channel could encourage adoption. Furthermore, the lack of significant relationship to direct incentives suggests that non-price barriers are in place. Thus, if the adoption of mobile commerce remains low, consumers must not have positive perceptions of mobile commerce's performance or may consider the effort to use the channel too high. This is supported by observations about the current state of mobile commerce, which is that mobile commerce sites and solutions are often difficult to use, technologically complicated, and actually present barriers to the user (Meola, 2016). Thus, if firms want to encourage mobile commerce, they need to improve the underlying technological functionality and usability, rather than try to promote social acceptance or 
use financial incentives. This could include, for example, ensuring that mobile commerce sites do work consistently on different technological platforms and using cleaner, less difficult designs for their mobile websites. However, the significant social barriers to adoption also mean that retailers need to work harder to communicate with consumers about the benefits of mobile shopping and ensure that they are really prepared to deliver with an omni-channel strategy. These strategies will help to ensure that consumers are infromed about the omni-channel strategy and what it can offer them, which would increased the perceived risk of shopping online via mobile apps.

This research provides novelty in that it is one of the few studies to examine consumer channel switching to mobile commerce. However, it is also limited in several important ways. The research only included Thai consumers, who have particular technological contexts and a specific retail environment. It also was conducted as a cross-sectional study, which limits the insights into changing conditions. There are clearly more opportunities available for research into retail channel switching, and this research is likely to become more important as the number of available retail channels proliferates. This area of research is likely to be of signfiicant concern to retailers adopting omni-channel marketing strategies and should be prioritized.

\section{References}

Ajzen, I. (2008). Consumer attitudes and behavior. In C. P. Haugtvedt, P. M. Herr, \& F. R. Cardes (Eds.), Handbook of Consumer Psychology (pp. 525-548). New York: Lawrence Erlbaum Associates.

Alkhunaizan, A., \& Love, S. (2012). What drives mobile commerce? An empirical evaluation of the revised UTAUT model. International Journal of Management and Marketing Academy, 2(1), 82-99.

Andrews, M. L., Benedicktus, R. L., \& Brady, M. K. (2010). The effect of incentives on customer evaluations of service bundles. Journal of Business Research, 63(1), 71-76.

Byrne, B. M. (2016). Structural equation modeling with AMOS: Basic concepts, applications and programming. New York: Routledge.

Chong, A. Y. (2013). Mobile commerce usage activities: The roles of demographic and motivation variables. Technological Forecasting and Social Change, 80(7), 1350-1359.

Dwivedi, Y. K., Rana, N. P., Chen, H., \& Williams, M. D. (2011). A meta-analysis of the Unified Theory of Acceptance and Use of Technology (UTAUT). In M. Nüttgens, A. Gadatch, K. Kautz, I. Schirmer, \& N. Blinn (Eds.), Governance and Sustainability in Information Systems. Managing the Transfer and Diffusion of IT. (Vol. 366). Berlin: Springer Berlin Heidelberg.

Falk, T., Schepers, J., Hammerschmidt, M., \& Bauer, H. H. (2007). Identifying cross-channel dissynergies for multichannel service providers. Journal of Service Research, 10(2), 143-160.

Gensler, S., Leeflang, P. S., \& Skiera, B. (2011). Impact of online channel use on customer revenues and costs to serve: Considering product portfolios and self-selection. International Journal of Research in Marketing, 29(2), 192-201.

Goldsmith, R. E. (2009). Electronic word of mouth. In Electronic Commerce: Concepts, methodologies, tools and applications (pp. 2143-2149). New York: IGI Global.

Heitz-Spahn, S. (2013). Cross-channel free-riding consumer behavior in a multichannel environment: An investigation of shopping motives, sociodemographics and product categories. Journal of Retailing and Consumer Services, 20, 570-578.

Jaradat, M. R., \& Al Rababaa, M. S. (2013). Assessing key factor that influence on the acceptance of mobile commerce based on modified UTAUT. International Journal of Business and Management, 8(23), 102112.

Kardes, F. R., Cronley, M. L., \& Cline, T. W. (2011). Consumer behavior. Andover: South-Western Cengage Learning.

Kauffman, R. J., Lee, D., Lee, J., \& Yoo, B. (2009). A hybrid firm's pricing strategy in electronic commerce under channel migration. International Journal of Electronic Commerce, 14(1), 11-54.

Lin, C., \& Anol, B. (2008). Learning online social support: An investigation into network information technology based on UTAUT. CyberPsychology and Behavior, 11(3), 268-272.

Maity, M., \& Dass, M. (2014). Consumer decision-making across modern and traditional channels: E-commerce, m-commerce, in-store. Decision Support Systems, 61, 34-46.

Meola, A. (2016, October 27). The Rise of M-Commerce: Mobile Shopping Stats \& Trends . Retrieved from Business Insider: http://uk.businessinsider.com/mobile-commerce-shopping-trends-stats-2016-10

Min, Q., Ji, S., \& Qu, G. (2008). Mobile commerce user acceptance study in China: A revised UTAUT model. Tsinghua Science and Technology, 13(3), 257-264. 
Neslin, S. A., \& Shankar, V. (2009). Key issues in multichannel customer management: Current knowledge and future directions. Journal of Interactive Marketing, 23(1), 70-81.

Okazaki, S. (2008). Determinant factors of mobile-based word-of-mouth campaign referral among Japanese adolescents. Psychology and Marketing, 25(8), 714-731.

Okazaki, S. (2009). Social influence model and electronic word of mouth: PC versus mobile internet. International Journal of Advertising, 28(3), 439-472.

Okazaki, S., \& Mendez, F. (2013). Exploring convenience in mobile commerce: Moderating effects of gender. Computers in Human Behavior, 29(3), 1234-1342.

Pookulangara, S., Hawley, J., \& Xiao, G. (2011). Explaining consumers' channel-switching behavior using the theory of planned behavior. Journal of Retailing and Consumer Services, 18(4), 311-321.

Solomon, M. R., Bamossy, G. J., Askegaard, S. T., \& Hogg, M. K. (2013). Consumer behaviour: A European perspective (5th ed.). London: Pearson.

Statista. (2016). Internet users in Asian countries who have made a purchase via mobile phone in 4th quarter 2015 . Retrieved from Statista: https://www.statista.com/statistics/255214/mobile-commerce-penetrationin-asia-pacific-countries/

Sue, V. M., \& Ritter, L. A. (2012). Conducting online surveys (2nd ed.). Thousand Oaks, CA: Sage Publications.

Sun, T., Youn, S., Wu, G., \& Kuntaraporn, M. (2006). Online word-of-mouth (or mouse): An exploration of its antecedents and consequences. Journal of Computer-Mediated Communication, 11(4), 1104-1127.

Venkatesh, V., Morris, M. G., Davis, G. B., \& Davis, F. D. (2003). User acceptance of information technology: Toward a unified view. MIS Quarterly, 27(3), 425-478.

Verhoef, P. C., Kannan, P. K., \& Inman, J. J. (2015). From multi-channel retailing to omni-channel retailing: Introduction to the special issue on multi-channel retailing. Journal of Retailing, 91(2), 174-181.

Wang, H., \& Wang, S. (2010). User acceptance of mobile Internet based on the Unified Theory of Acceptance and Use of Technology: Investigating the determinants and gender differences. Social Behavior and Personality, 38(3), 415-426.

Westland, J. C. (2010). Lower bounds on sample size in structural equation modeling. Electronic Commerce Research and Applications, 9(6), 476-487.

Wu, H., \& Wang, S. (2005). What drives mobile commerce? An empirical evaluation of the revised technology acceptance model. Information and Management, 42, 719-729.

\section{Appendix: Questionnaire}

Table 2: Questionnaire items

\begin{tabular}{|c|c|c|}
\hline Scale (Item) & Statements & \begin{tabular}{|c} 
Reliability \\
$(\alpha)$
\end{tabular} \\
\hline $\begin{array}{l}\text { Performance } \\
\text { Expectancy (PE) }\end{array}$ & $\begin{array}{l}\text { - Shopping online gives me the same choice as shopping in stores. (PE1) } \\
\text { - If I shop online I will receive my goods fast enough to suit me (PE2) } \\
\text { - Shopping online meets my needs (PE3) }\end{array}$ & 0.832 \\
\hline $\begin{array}{l}\text { Effort Expectancy } \\
\text { (EE) }\end{array}$ & $\begin{array}{l}\text { - Shopping online is easier than shopping in stores (EE1) } \\
\text { - Shopping online is not hard (EE2) } \\
\text { - I can shop online without difficulty (EE3) }\end{array}$ & 0.871 \\
\hline $\begin{array}{l}\text { Social Influence } \\
\text { (SI) }\end{array}$ & $\begin{array}{l}\text { - My friends influence my shopping habits (SI1) } \\
\text { - My family influences my shopping habits (SI2) } \\
\text { - I ask people about where I should buy things (SI3) }\end{array}$ & 0.803 \\
\hline $\begin{array}{l}\text { Online Social } \\
\text { Support (OSS) }\end{array}$ & $\begin{array}{l}- \text { I read reviews online for products I buy (OSS1) } \\
\text { - I ask for feedback online about where I should buy products I want (OSS2) } \\
\text { - Reading about other people's purchases helps me make up my mind about shopping online } \\
\text { (OSS3) }\end{array}$ & 0.912 \\
\hline Convenience (CO) & $\begin{array}{l}\text { - I can shop online anywhere (CO1) } \\
\text { - I can shop online anytime (CO2) } \\
\text { - I can find what I want online easily (CO3) }\end{array}$ & 0.807 \\
\hline $\begin{array}{l}\text { Direct Incentives } \\
\text { (DI) }\end{array}$ & $\begin{array}{l}\text { - When my friends offer referrals to online shops I try them (DI1) } \\
\text { - Discounts can make me consider changing where I shop (DI2) } \\
\text { - Reducing the cost of changing shops makes me more likely to shop somwehre new (DI3) }\end{array}$ & 0.901 \\
\hline $\begin{array}{l}\text { Switching } \\
\text { Intentions (SWI) }\end{array}$ & $\begin{array}{l}\text { Scenario: A store where you currently shop in store to buy food and housewares, has just } \\
\text { opened up online shopping for all their products. You can now buy and return products both } \\
\text { online and in stores, with no difference between them. What is your response? } \\
\text { - I am likely to try the online shopping (SWI1) } \\
\text { - I am eager to try online shopping (SWI2) } \\
\text { - I would consider online shopping at this store (SW3) }\end{array}$ & 0.932 \\
\hline
\end{tabular}

Note: All items assessed on a five-point Likert scale: 1 = Completely Disagree, 5 = Completely Agree 